\title{
Karyotypic Polymorphism in Paris hexaphylla Cham., with Special Reference to Its Origin and to the Meiotic Chromosome Behavior
}

\author{
By \\ Tutomu Haga \\ Botanical Institute, Faculty of Science, \\ Hokkaido Imperial University, Sapporo
}

Since its first discovery by NAWASCHIN (1912) in Galtonia candicans, karyotypic polymorphism has been fully identified in many other plants ( $c f$. KUHN 1928 and ONO 1935). Interestingly recent investigations dealing with the karyotypic aberration have furnished, in certain cases, karyological bases for such genetic phenomena as balanced lethal mechanism (MALINOWSKI 1935), partial sterility (NAVASHin 1933), vigorousty (Medwedwa 1929) etc. On the contrary in certain cases it is inferred that the polymorphism is concerned only with the genetically inert portion of the chromosome (LESLEY and LESLEY 1935).

The polyploids and karyotypes in Paris hexaphylla Cham. ${ }^{1)}$ were found by Gотон and Sтоw (1930),"-) and preliminarily reported by the present writer (1934 a,b and 1935). Studying the same plant the writer confirmed the observations by the former investigators, revealing six karyotypes of which four are diploid $(2 \mathrm{n}=10)$ and two triploid $(2 \mathrm{n}=15)$.

In this paper the writer gives a detailed description of the somatic complements of six karyotypes with some features of the meiotic chromosome behavior.

\section{Material and Methods}

The material used was collected at the foot of Mt. Maruyama near Sapporo in Spring, and preserved in pots containing soil till the niddle of September (soil temperature $17-20^{\circ} \mathrm{C}$ ) when the root-tips were fixed. Observations of somatic complements were all based on chloralisated root-tip cells, which were prepared as follows: Rootlets were first immersed together with rhizomes in 1 percent chloralhydrate $\left(18^{\circ} \mathrm{C}\right)$, rinsed in tap-water $\left(13-14^{\circ} \mathrm{C}\right)$ for 1 hour respectively, allowed to remain for $2-3$ hours on wet filter-paper in a large moistened PETRI dish kept in darkness $\left(19-20^{\circ} \mathrm{C}\right)$; then the root-tips were cut and fixed in LA Cour 2BE. All the material was pre-treated under almost the same condition as shown in parentheses. After the ordinary paraffin-section method, they were stained with gentian-violet according to NEwToN's schedule.

1) In the previous papers (HAGA $1934 \mathrm{a}, \mathrm{b}$ ) the synonymous name $P$. quadrifolia L. var. obovata REGEL et TIL. was used.

2) See also Gотон (1933) and Stow (1935). 
Meiosis in PMCs was observed in the middle of May using young flower buds collected directly from their natural habitat, employing BELLING's iron aceto-carmine method.

All drawings were made with an ABBÉ camera lucida using a LEITZ 1/12 oil immersion objective and a LeIrz periblan $\times 15$ eye piece, giving a magnification of $\times 1750$ diameters. They were reduced for reproduction to the scale indicated.

\section{Observations}

Before going further, effect of the chloralisation must be inspected because the details of the somatic complements have been based on the treated materials. By the chloralisation the chromosomes are made short and less twisted, but without any conspicuous increase in chromatid diameter. The kinetic constriction becomes very pronounced and elongated, but the long akinetic constriction which separates the trabant from the chromosome bulk remains intact. Thus the influence of chloralisation differs in two functionaly and structurally different constrictions (cf. Figs. 1-6 with Figs. 15-16 in HAGA 1934a). Further

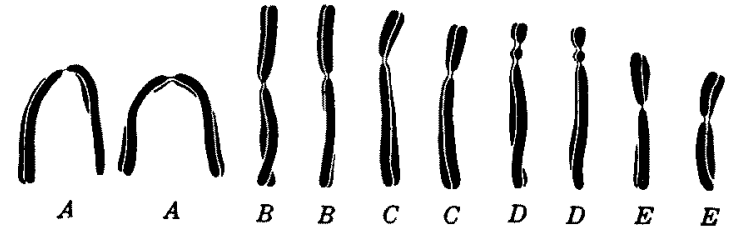

2

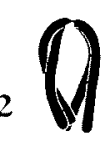

$A$
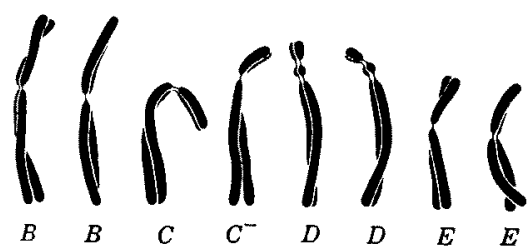

3
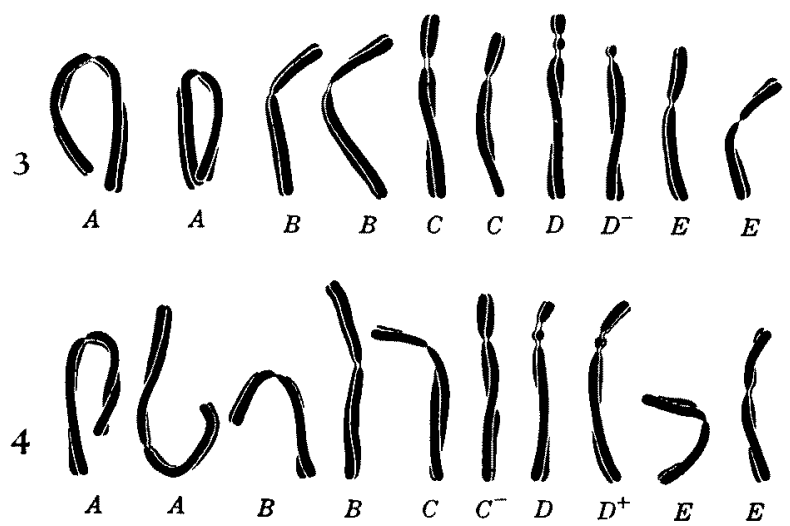

Figs. 1-4. Somatic complements of the four diploid karyo. types. All the chromosomes from one complete metaphase plate are alined. 1: Type $C C D D$. 2: Type $C C^{-} D D$. 3: Type $C C D D^{-} \quad 4:$ Type $C C^{-} D D^{+} \times 1225$. the chloralisated chromosomes do not make a normal metaphase plate (cf. HAGA 1935).

The treatment affects the chromosomes in the manner above mentioned, but, as will be seen in Tables 1-9, the relative lengths of the component chromosomes in a complement as well as the relative positions of the constrictions of given chromosomes are not altered. Such an effect is well shown, especially, in the comparison of two complements from one and the same individual which markedly differ in the degree of shortening ( $c f$. Tables 7 and 8).

In view of the above findings the following observations will be taken to represent, though in relative values, the natural situations of the chromosome complements. The chromo- 
some lengths of the complements presented in Figures 1-6 are about $60-70$ percent of the lengths measured in non-treated material by the writer (HAGA 1934a). The previous chromosome designations $A, B, C, D$ and $E$ have also been adopted in the present paper.

\section{Somatic complements of the diploid forms ${ }^{1)}$}

1. Type $C A D D$. All the five pairs are contained in a homozygous condition, representing the unique type of the diploid homozygote ${ }^{2)}$ (Fig. 1).

2. Type $C C^{-} D D$. One of the $C$-pair is deficient as to its short arm, deficiency amounting to an average 21.5 percent of the normal short arm length. Remaining four pairs are unaltered (Fig. 2).

3. Type $C C D D^{-}$One of the $D$-pair is deprived of its trabant, otherwise entirely normal (Fig. 3).

4. Type $C C^{-} D D^{+}$One of the $C$-pair is deficient of its short arm, averaging in deficiency 21.4 percent of the normal short arm length. The length of trabant of one of the $D$-pair is increased, showing about 29.1 percent of its whole length as the surplus length (Fig. 4).

Among the four karyotypes above described the first and the third are the same as those found by GoTOH and STOW (1930) and designated by STOW (1935) as $\mathrm{II}_{2}$ and $\mathrm{II}_{1}$ respectively. The other two were found anew by the present study.

5

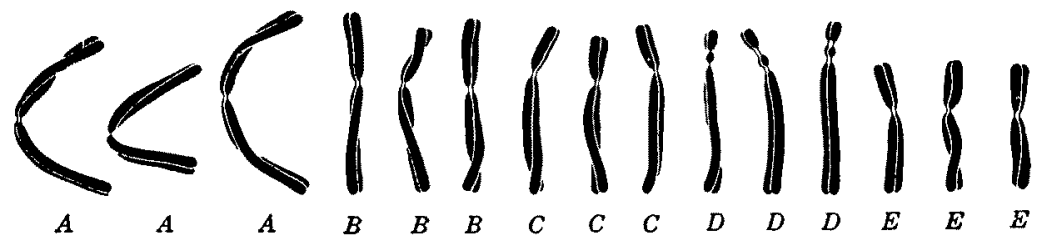

6

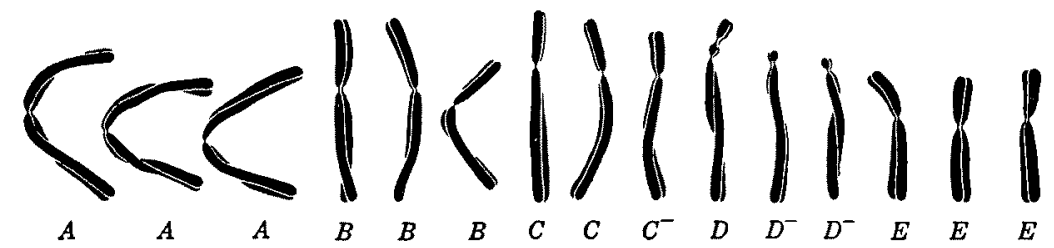

Figs. 5-6. Somatic complements of the two triploid karyotypes. All the chromosomes from one complete metaphase plate are alined. 5: Type $C C C D D D$. 6: Type $C C C^{-} D D^{-} D^{-} . \quad \times 1225$.

1) The sign - indicates length deficit and + surplus. Previously $D$ chromosome has been designated with $d T$ and $D^{-}$-chromosome with $d_{0}$ (HAGA $1934 \mathrm{a}, \mathrm{b})$.

2) The terms homo- and heterozygote were used as to the condition of morphological characters of the pair of chromosomes. 


\section{Somatic complement of the triploid forms}

1. Type $C C C D D D$. In every chromosome type all three homologues are quite identical with one another in their morphology; apart from the number of homologues there is seen no difference between this and diploid $C C D D$ type (Fig. 5).

2. Type $C C C^{-} D D^{-} D^{-}$One of the three $C$-chromosomes is deficient as to its short arm, the deficiency being 21.4 percent of the normal length of the short arm. Furthermore, two of the three $D$ chromosomes are deprived of their trabants (Fig. 6).

The first type is identical with GoToH and STow's $\mathrm{III}_{3}$, and the second one is also, probably, the same as their $\mathrm{III}_{1}$ because the material was collected from the same habitat in the botanical garden of our university, where they grew under wild conditions, but they overlooked the deficient $C$-chromosome. One triploid form found by the previous investigators $\left(\mathrm{III}_{2}\right)$ which comprises two $D$ - and one $D^{-}$-chromosomes instead of three $D$ 's was missed by the present writer.

\section{Comparison of the karyotypes}

In order to clear up more fully the details of the chromosome complements of the six karyotypes, the writer made precise measurements. To make the technical errors as slight as possible, no special measuring technic was applied, selecting the complete metaphase plate in a single cell revealing the actual lengths, at least, of all the chromosomes composing a haploid set, namely only when they are lying horizontally along their whole lengths. In a majority of cases almost all the components of a complement were measured. The differences in length as well as form percent between the pair were too small to be considered significant, so that only the mean values were tabulated in Tables 1-8, excluding $C^{-}, D^{-}$, and $D^{+}$-chromosome. Degrees of shortening by the chloralisation were shown with lengths in percent of the lengths in non-treated complement (Table 1), which was indicated by $\mathrm{S} \%$.

Tables 1-8.1) Mean values of the measurements on unaltered chromosomes in a single complement of eight karyotypes

1.") $C C D D$

\begin{tabular}{|c|c|c|c|c|c|}
\hline Chromosome & \multicolumn{2}{|c|}{ Actual length in } & $\mathrm{L} \%$ & $F \%$ & $\mathrm{~S} \%$ \\
\hline $\begin{array}{l}A \\
B \\
C\end{array}$ & $\begin{array}{l}16.8+16.5= \\
15.8+10.3= \\
17.1+5.6=\end{array}$ & $\begin{array}{l}33.3 \\
26.1 \\
22.7\end{array}$ & $\begin{array}{l}26.9 \\
21.1 \\
18.4\end{array}$ & $\begin{array}{l}49.5 \\
39.6 \\
24.7\end{array}$ & $\begin{array}{l}100.0 \\
100.0 \\
100.0\end{array}$ \\
\hline$D$ & $18.8+1.1+2.3=$ & 22.2 & 17.9 & $\left\{\begin{array}{r}5.0 \\
10.4\end{array}\right.$ & 100.0 \\
\hline$E$ & $11.1+8 \cdot 3=$ & 19.4 & 15.7 & 42.8 & 100.0 \\
\hline Sum & & 123.7 & 100.0 & Mean & 100.0 \\
\hline
\end{tabular}

1) Position of constriction is indicated by the mark $t$, and the sum is the whole length of the chromosome. $L \%$ and $F \%$ indicate length and form percent respectively, the former representing the whole length of a chromosome in percent of total sum of chromosome lengths in a haploid set and the latter 
2. $C C D D$

\begin{tabular}{|c|c|c|c|c|c|}
\hline Chromosome & \multicolumn{2}{|c|}{ Actual leng th in $\mu$. } & $\mathrm{L} \%$ & $\mathrm{~F} \%$ & $\mathrm{~S} \%$ \\
\hline $\begin{array}{l}A \\
B \\
C\end{array}$ & $\begin{array}{l}11.7+11.7 \\
10.2+6.9 \\
12.0+4.6\end{array}$ & $\begin{array}{l}=23.4 \\
=17.1 \\
=16.6\end{array}$ & $\begin{array}{l}27.4 \\
20.0 \\
19.5\end{array}$ & $\begin{array}{l}50.0 \\
40.4 \\
27.7\end{array}$ & $\begin{array}{l}70.3 \\
65.5 \\
73.1\end{array}$ \\
\hline$D$ & $12.6+1.0+2.0$ & $=15.6$ & 18.3 & $\left\{\begin{array}{r}6.4 \\
12.8\end{array}\right.$ & 70.3 \\
\hline$E$ & $7.6+5.0$ & $=12.6$ & 14.8 & 39.7 & 64.9 \\
\hline Sum & & 85.3 & 100.0 & Mean & 68.8 \\
\hline
\end{tabular}

3. $C C^{-} D D$

\begin{tabular}{|c|c|c|c|c|c|}
\hline Chromosome & \multicolumn{2}{|c|}{ Actual length in $\mu$} & $\mathrm{L} \%$ & $\mathrm{~F} \%$ & $\mathrm{~S} \%$ \\
\hline $\begin{array}{l}A \\
B \\
C\end{array}$ & $\begin{array}{l}13.7+13.6 \\
11.6+8.6 \\
12.9+4.9\end{array}$ & $\begin{array}{l}=27.3 \\
=20.2 \\
=17.8\end{array}$ & $\begin{array}{l}28.2 \\
20.9 \\
18.4\end{array}$ & $\begin{array}{l}49.8 \\
42.6 \\
27.5\end{array}$ & $\begin{array}{l}82.0 \\
77.4 \\
78.4\end{array}$ \\
\hline$D$ & $13.7+1.0+1.9$ & $=16.6$ & 17.1 & $\left\{\begin{array}{r}6.0 \\
11.4\end{array}\right.$ & 74.8 \\
\hline$E$ & $8.6+6.3$ & $=14.9$ & 15.4 & 42.3 & 76.8 \\
\hline Sum & & 96.8 & 100.0 & Mean & 77.9 \\
\hline
\end{tabular}

4. $C C D D^{-}$

\begin{tabular}{|c|c|c|c|c|c|}
\hline Chromosome & \multicolumn{2}{|c|}{ Actual length in } & $\mathrm{L} \%$ & $\mathrm{~F} \%$ & $\mathrm{~S} \%$ \\
\hline $\begin{array}{l}A \\
B \\
C\end{array}$ & $\begin{array}{r}12.0+11.4 \\
10.9+7.4 \\
11.5+4.6\end{array}$ & $\begin{array}{l}=23.4 \\
=18.3 \\
=16.1\end{array}$ & $\begin{array}{l}27.2 \\
21.3 \\
18.7\end{array}$ & $\begin{array}{l}48.7 \\
40.4 \\
28.6\end{array}$ & $\begin{array}{l}70.3 \\
70.1 \\
70.9\end{array}$ \\
\hline$D$ & $12.6+1.0+2.0=$ & $=15.6$ & 18.2 & $\left\{\begin{array}{r}6.4 \\
128\end{array}\right.$ & 70.3 \\
\hline$E$ & $7.4+5.1$ & $=12.5$ & 14.6 & $\begin{array}{r}112.8 \\
40.8\end{array}$ & 64.4 \\
\hline Sum & & 85.9 & 100.0 & Mean & 69.2 \\
\hline
\end{tabular}

5. ${ }^{3)} C C-D D^{+}$

\begin{tabular}{|c|c|c|c|c|c|}
\hline Chromosome & \multicolumn{2}{|c|}{ Actual length in } & $\mathrm{L} \%$ & $\mathrm{~F} \%$ & $\mathrm{~S} \%$ \\
\hline $\begin{array}{l}A \\
B \\
C\end{array}$ & $\begin{array}{r}14.9+14.3= \\
12.6+9.0= \\
15.1+5.1=\end{array}$ & $\begin{array}{l}=29.2 \\
=21.6 \\
=20.2\end{array}$ & $\begin{array}{l}27.7 \\
20.5 \\
19.4\end{array}$ & $\begin{array}{l}49.0 \\
41.7 \\
25.2\end{array}$ & $\begin{array}{l}87.6 \\
82.8 \\
89.0\end{array}$ \\
\hline$D$ & $14.3+1.1+2.3=$ & $=17.7$ & 16.8 & $\left\{\begin{array}{r}6.2 \\
13.0\end{array}\right.$ & 79.7 \\
\hline$E$ & $9.4+6.9$ & $=16.6$ & 15.7 & 41.6 & 85.6 \\
\hline Sum & & 105.3 & 100.1 & Mean & 84.9 \\
\hline
\end{tabular}

the short arm length in percent of the whole length of a chromosome. The upper one of the two form percents of $D$-chromosome represents that of the short arm and the lower that of the trabant.

2) Non-treated complement and the same one given in Table 4 of the previous paper (HAGA 1934 a). Chromosome lengths in this complement were. used as the standard lengths for the calculation of $\mathrm{S} \%$ 's.

$3)$, 4) and 5) In these three complements the long arms of $D$ 's are slightly shorter than those of $C$ 's. But these mean nothing else than the expectable variations in the contraction grades between two independent chromo. somes for the normal relations between $C$ - and $D$-chromosome were ascertained repeatedly in the same individuals. The complements in Tables 7 and 8 are taken from the same individual. 
6. $C C C D D D$

\begin{tabular}{|c|c|c|c|c|c|}
\hline Chromosome & \multicolumn{2}{|c|}{ Actual length in $\mu$} & $L \%$ & F;o & $\mathrm{S} \%$ \\
\hline $\begin{array}{l}A \\
B \\
C\end{array}$ & $\begin{array}{r}14.0+13.7 \\
12.0+8.9 \\
13.7+5.1\end{array}$ & $\begin{array}{l}=27.7 \\
=20.9 \\
=18.8\end{array}$ & $\begin{array}{l}27.5 \\
20.8 \\
18.7\end{array}$ & $\begin{array}{l}49.5 \\
42.6 \\
27.1\end{array}$ & $\begin{array}{l}83.2 \\
80.1 \\
82.8\end{array}$ \\
\hline$D$ & $14.9+1.0+2.0$ & $=17.9$ & 17.8 & $\left\{\begin{array}{r}5.6 \\
11.2\end{array}\right.$ & 80.6 \\
\hline$E$ & $9.2+6.1$ & $=15.3$ & 15.2 & 39.9 & 78.9 \\
\hline Sum & & 100.6 & 100.0 & Mean & 81.1 \\
\hline
\end{tabular}

7.') $C C C-D D^{-} D^{-1}$

\begin{tabular}{|c|c|c|c|c|c|}
\hline Chromosome & \multicolumn{2}{|c|}{ Actual length in } & $\mathrm{L} \%$ & F\% & $\mathrm{S} \%$ \\
\hline $\begin{array}{l}A \\
B \\
C\end{array}$ & $\begin{array}{r}10.9+10.6 \\
9.1+6.9 \\
11.1+3.9\end{array}$ & $\begin{array}{l}=21.5 \\
=16.0 \\
=15.0\end{array}$ & $\begin{array}{l}28.1 \\
20.9 \\
19.6\end{array}$ & $\begin{array}{l}49.3 \\
43.1 \\
26.0\end{array}$ & $\begin{array}{l}64.6 \\
61.3 \\
66.1\end{array}$ \\
\hline$D$ & $10.6+0.7+1.4$ & $=12.7$ & 16.6 & $\left\{\begin{array}{r}5.5 \\
11.0\end{array}\right.$ & 57.2 \\
\hline$E$ & $6.3+5.1$ & $=11.4$ & 14.9 & 44.7 & 58.8 \\
\hline Sum & & 76.6 & 100.1 & Mean & 61.6 \\
\hline
\end{tabular}

8. ${ }^{5} \quad C C C^{-} D D^{-D-1 I}$

\begin{tabular}{|c|c|c|c|c|c|}
\hline Chromosome & \multicolumn{2}{|c|}{ Actual length in $\mu$} & $\mathrm{L} \%$ & $\mathrm{~F} \%$ & $\mathrm{~S} \%$ \\
\hline $\begin{array}{l}A \\
B \\
C\end{array}$ & $\begin{array}{l}8.5+8.2= \\
6.8+5.0= \\
8.0+3.3=\end{array}$ & $\begin{array}{l}16.7 \\
11.8 \\
11.3\end{array}$ & $\begin{array}{l}28.9 \\
20.4 \\
19.6\end{array}$ & $\begin{array}{l}49.1 \\
42.4 \\
29.2\end{array}$ & $\begin{array}{l}50.2 \\
45.2 \\
49.8\end{array}$ \\
\hline$D$ & $7.7+0.7+1.4=$ & 9.8 & 17.0 & $\left\{\begin{array}{r}7.1 \\
14.3\end{array}\right.$ & 44.1 \\
\hline$E$ & $4.8+3.4=$ & 82 & 14.2 & 41.5 & 42.3 \\
\hline Sul & & 67.8 & 100.1 & Mean & 46.3 \\
\hline
\end{tabular}

As a matter of fact, the chromosome is not an absolute thing but a relative one, so that though the relative values are highly stable, they also vary within a small range. Here it is important to note that the writer has found in the statistical data on one and the same individual of Trillium kamtschaticum that the absolute lengths and the form percents of a given chromosome type vary far more than the extent found between the same chromosome types of the different karyotypes of this plant ( $c f$. HAGA 1934a). Moreover it must be emphasized that the shorter the chromosome or the chromosome part relatively the greater is the observational and measuring error. The variation ranges of absolute lengths in different karyotypes, which are inspectable most simply with $\mathrm{S} \%$, do not extend over the range found between two different complements in the same individual ( $c f$. Table 7 and 8 ).

Thus, if one makes a careful comparison between the results in Tables 1-9, he will be convinced that all the unaltered chromosomes included in six karyotypes are identical and remain unaffected by the genotypic change which may necessarily be caused by the structural hybridity. Averaging up the data in Tables 1-8, mean values of the normal haploid set were obtained, which are presented in Table 9 and diagrammatically in Figure 7. 
Table 9. Averaging the results in Tables 1-8

\begin{tabular}{|c|c|c|c|c|c|c|}
\hline Chromosome & Actual length in & $\approx$ & $\mathrm{L} \%$ & $\sigma$ & $\mathrm{F} \%$ & $\sigma$ \\
\hline$A$ & $12.8+12.5=25.3$ & \pm 4.8031 & 27.6 & \pm 0.6072 & 49.4 & \pm 0.4016 \\
\hline$B$ & $11.1+7.9=19.0$ & $\begin{array}{r}3.9850 \\
+3.0\end{array}$ & 20.7 & \pm 0.3921 & 41.6 & 1.2344 \\
\hline$C$ & $12.7+4.7=17.4$ & \pm 3.2280 & 19.0 & \pm 0.5037 & 27.0 & \pm 1.4866 \\
\hline$D$ & $13.2+1.0+1.9=16.1$ & \pm 3.4467 & 17.6 & \pm 0.6354 & $\left\{\begin{array}{r}6.2 \\
118\end{array}\right.$ & \pm 0.6113 \\
\hline$E$ & $8.1+5.7=13.8$ & \pm 3.2187 & 15.1 & \pm 0.5012 & 41.3 & \pm 1.5696 \\
\hline Sum & 91.6 & \pm 18.5545 & 100.0 & & & \\
\hline
\end{tabular}

Now we are for a comparison of the structural changes which are found in different karyotypes. The following data were based on the comparison of a pair of normal and changed chromosome that were measured together in one and the same metaphase plate where the two were lying in a horizontal plane along their whole lengths. The measurements were carried out on about ten pairs in each case, resulting as in Tables 10 and 11 . With regard to the long arm there was no length difference between altered and unaltered chromosomes, notwithstanding the chromosome type concerned. So no special mention will be made in this respect.

Table 10. Comparison of $C^{-}$chromosomes in three karyotypes

\begin{tabular}{c|cc|cc}
\hline Karyotype & Deficiency & $\sigma$ & F\% & $\sigma$ \\
\hline$C C C^{-} D D$ & 21.5 & \pm 1.1510 & 23.1 & \pm 0.1000 \\
$C C C^{-} D D^{+}$ & 21.4 & \pm 1.5732 & 22.8 & \pm 1.0000 \\
$C C C^{-} D D^{-} D^{-}$ & 21.4 & \pm 2.1954 & 22.8 & \pm 1.0165 \\
\hline Mean & 21.4 & \pm 1.8253 & 22.9 & \pm 0.3005
\end{tabular}

In Table 10 the deficit length of the short arm of the $C^{-}$-chromosome was represented in percent of the normal short arm length. Deficiency and form percent of the $C^{-}$-chromosomes which were found in three karyotypes $C C^{-} D D, C C^{-} D D^{+}$and $C C^{-} D D^{-} D^{-}$were almost in agreement with one another (Table 10). This suggests significantly the common origin of the $C^{-}$-chromosomes which is comprised, at present, in three different karyotypes.

The measurements showed 29.1 percent $(b= \pm 2.1221)$ of the whole length of the trabant of $D^{+}$-chromosome to be the surplus length. A comparison of the length percents

Table 11. Comparison of changed parts of the altered chromosomes with one another and with the corresponding parts of normal ones

\begin{tabular}{l|cc}
\multicolumn{1}{c|}{ L $\%$} & Mean \\
\hline Normal short arm of $C$ & $5.1 \pm 0.3518$ \\
Length of trabant of $D$ & $2.1 \pm 0.2031$ \\
Deficit length of short arm of $C^{-}$ & $1.1 \pm 0.0294$ \\
Surplus length of trabant of $D^{+}$ & $0.9 \pm 0.0390$
\end{tabular}


of the deficit length of $C^{-}$-chromosome and the surplus one of the $D^{+}$-chromosome revealed the interesting fact that the two values are almost agree with one another (Table 11). Thus it seems, though it may be somewhat premature to state it, that translocation of a small segment from the short arm of $C$-chromosome to the distal end of the trabant of $D$-chromosome may be

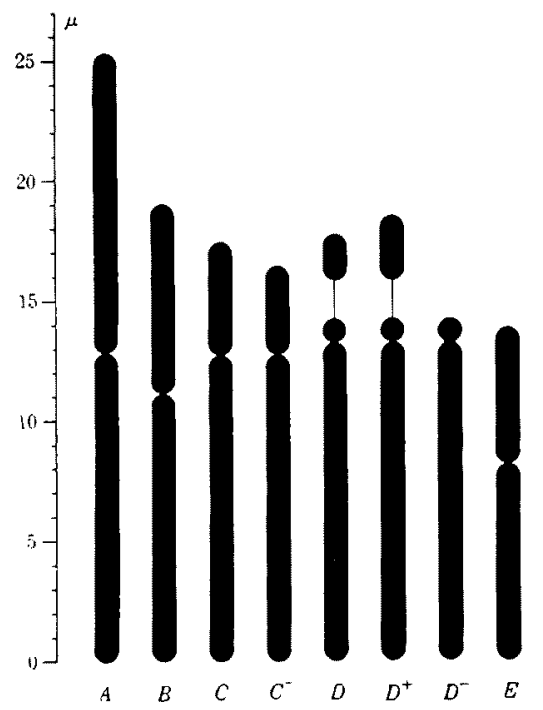

Fig. 7. Diagrammatic representation of the results in Tables, 9, 10 and 11. the origin of $\mathrm{C}^{-}$and $\mathrm{D}^{+}$-chromosome. Of course other interpretations are not impossible, however, the above mentioned seems the most favorable for the circumstances found.

The fact that the long arm lengths of $D$ - and $D^{-}$-chromosome are equal and the close comparison of the results in Tables 1-11 indicates that $D^{-}$-chromosome has been derived, very probably, from simple deletion of the entire part of the trabant of the $D$-chromosome.

From the above results three altered chromosomes $C^{-}, D^{+}$and $D^{-}$were represented diagrammatically in Figure 7, contrasting to the unaltered original ones.

\section{Meiosis in diploids}

Behavior during the prophase was not studied, but through all four karyotypes the meiosis occurs normally except for a somewhat frequent occurrence of non-pairing of one or two pairs, fragmentation and bridge-formation at metaphase and anaphase.

Metaphase pairing was regular, showing 5 bivalents paired at the region of kinetochore and rarely with additional interstitial chiasma (Figs. 8-9). Pairing of the heteromorphic pairs in heterozygous forms is not interrupted by the structural dissimilarities between the partners. Heteromorphic constitution was very clear in the $D$ - $D^{-}$bivalent with the repulsion between the heteromorphic short arms in the plane of reduction (Fig. 8), but it was indiscernible in $C-C^{-}$and $D-D^{+}$bivalents for the minute differences between the partners.

Meiotic processes from first to second anaphase and pollen forma- 


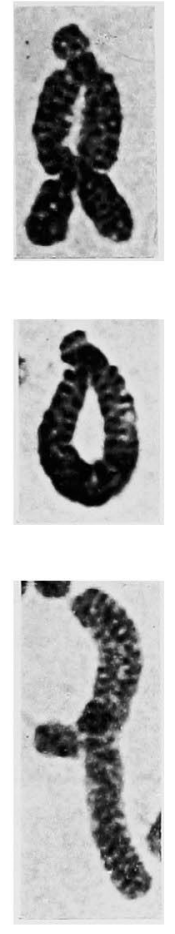

8

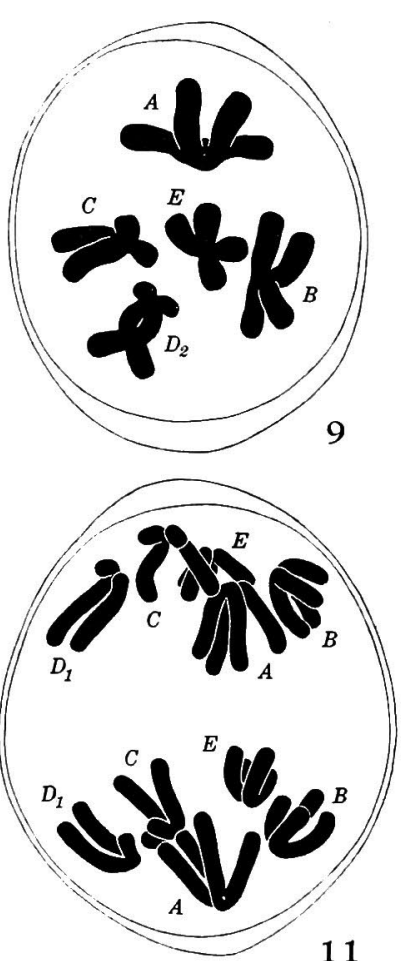

11

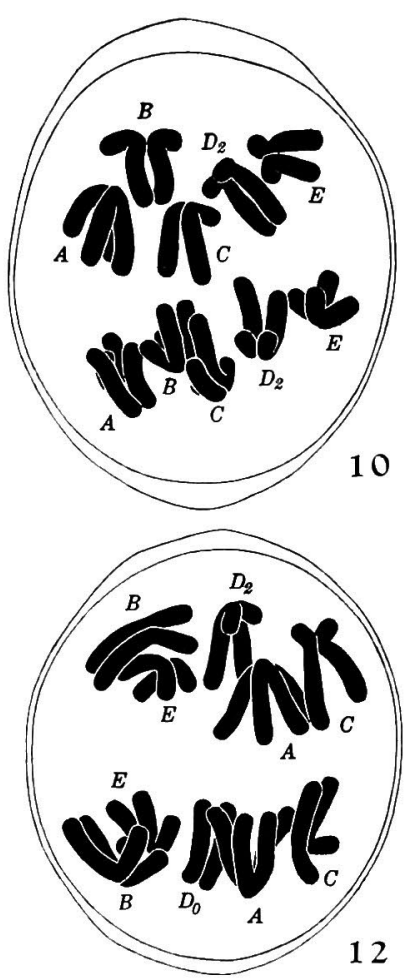

12

Figs. 8-12. Meiotic first divisions in PMCs. 8: Heteromorphic $D$ - $D^{-}$bivalents at first metaphases. Large satellited short arm is seen at the upper left and non-satellited short arm as a small head at the upper right in all three photos. Chiasma in the uppermost is interstitial, in the middle almost terminal and in the lowest is not formed or has slipped off till the metaphase. $\times 1463$. (Prof. H. Matsuura photo). 9-12: Subscript numerals under the $D$-type chromosomes indicate number of trabants. 1 and 2 representing the presence of one and two tranbants respectively and $o$ the absence of any. 9: Metaphase in type $C C D D$, showing $A$-bivalent two chiasmata at both sides near the kinetochore, and $D$-bivalent one interstitial chiasma. 10: Anaphase in type $C C D D$. 11-12: Anaphases in type $C C D D^{-}$, segregating $D-D^{-}$ bivalent equationally as to its short arm in Fig. 11, and reductionally in Fig. 12. $\times 870$.

tion are also regular (Figs. 10-15). With $D$ - $D^{-}$bivalent it was ascertained that the heteromorphic pair segregates reductionally as well as equationally at first anaphase, at least, as to its short arms (Figs. 11-12). If it segregates reductionally at first anaphase, then equationally at the second one, and vice versa (Figs. 14-15). The ratio reductional to equational segregation in $253 \mathrm{PMCs}$ was 1.0 : 5.3 , diverging from the ratios hitherto known with a moderate preponderance of the equational one ( $c f$. HUSKINS and SPIER 1934 and MATHER 1935). 


\section{Meiosis in triploids}

Details before metaphase were not studied. In general meiosis proceeds as in many other autotriploid plants, showing no difference

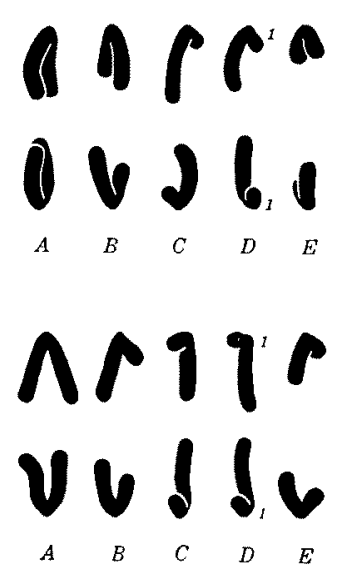

13
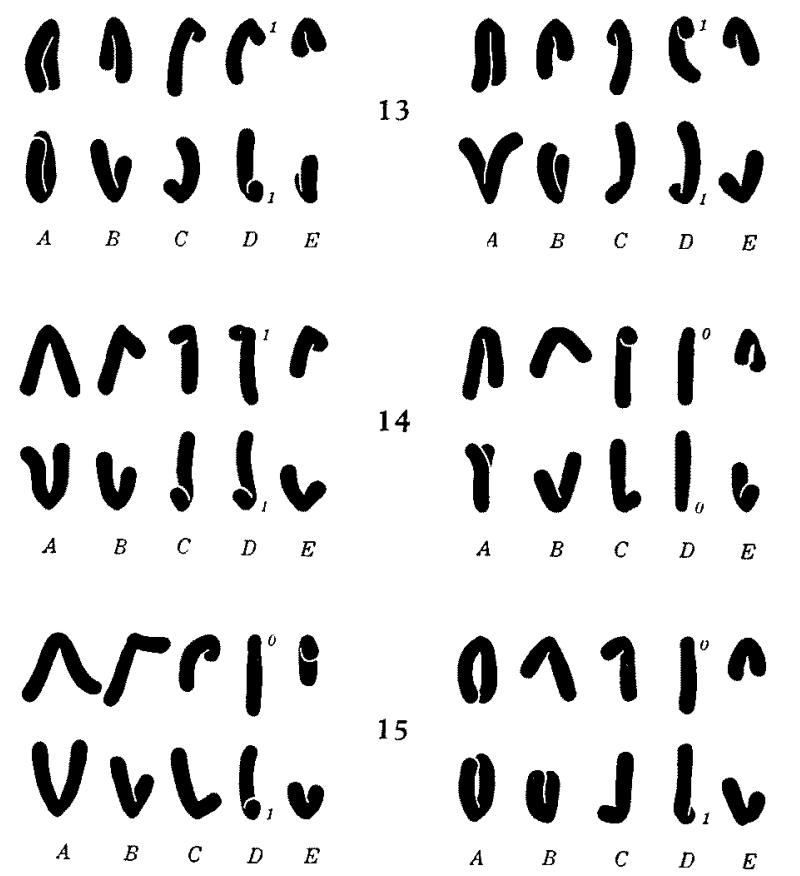

\section{4}
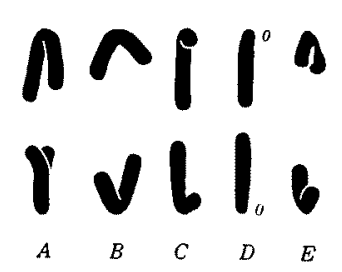

15
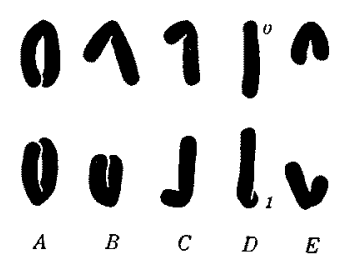

Figs. 13-15. Alinements of meiotic second anaphase chromosomes in two diplold karyotypes, being two divisions in a PMC shown separately at both sides of the Figure number. Daughter halves are faced up and down. Numerals beside the $D$-type chromosome indicate the presence (1) or absence $(o)$ of a trabant. 13: Type $C C D D . \quad 14-15$ : Type $C C D D^{-}$, showing in Figure 14 an equational segregation of the short arm of $D$-type chromosomes, and in

Figure 15 reductional segregation of them. $\times 870$. between the two karyotypes. Irregularities as those observed in diploids occur more frequently in triploids.

At metaphase 0-5 trivalents are seen, with a formation of 5 trivalents prevailing (Fig. 16). ${ }^{1)}$ The mode of pairing is the same as in diploids except the number of homologues (Fig. 16). The heteromorphic constitution of the $D-D^{-}-D^{-}$ trivalent was also clear with the repulsion between the heteromorphic short arms in the planes of reduction (Fig. 16). At first anaphase three homologues paired in a trivalent separate from one another and migrate to the poles (Figs. 17-19).

To make clear the mode of anaphase segregation 256 anaphase PMCs of the triploid form $C C C^{-} D D^{-} D^{-}$were studied, selecting only those which were believed to have been derived from the metaphases formed of 5 trivalents."

1) For details confer Haga (1937).

2) In this plant meiotic chromosomes are easily identifiable as in somatic complement (cf. Figs. 1-22). Thanks to this quality the metaphase pairing was able to deduce with reliable certainty, from a given disposition of the anaphase chromosomes ( $c f$. Figs. 10-12 and 17-19). 

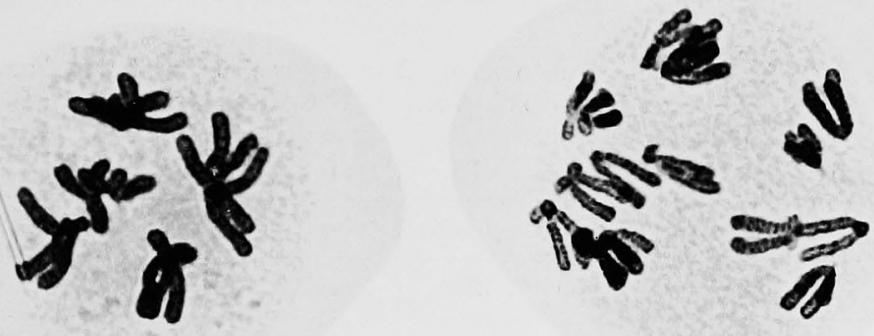

16
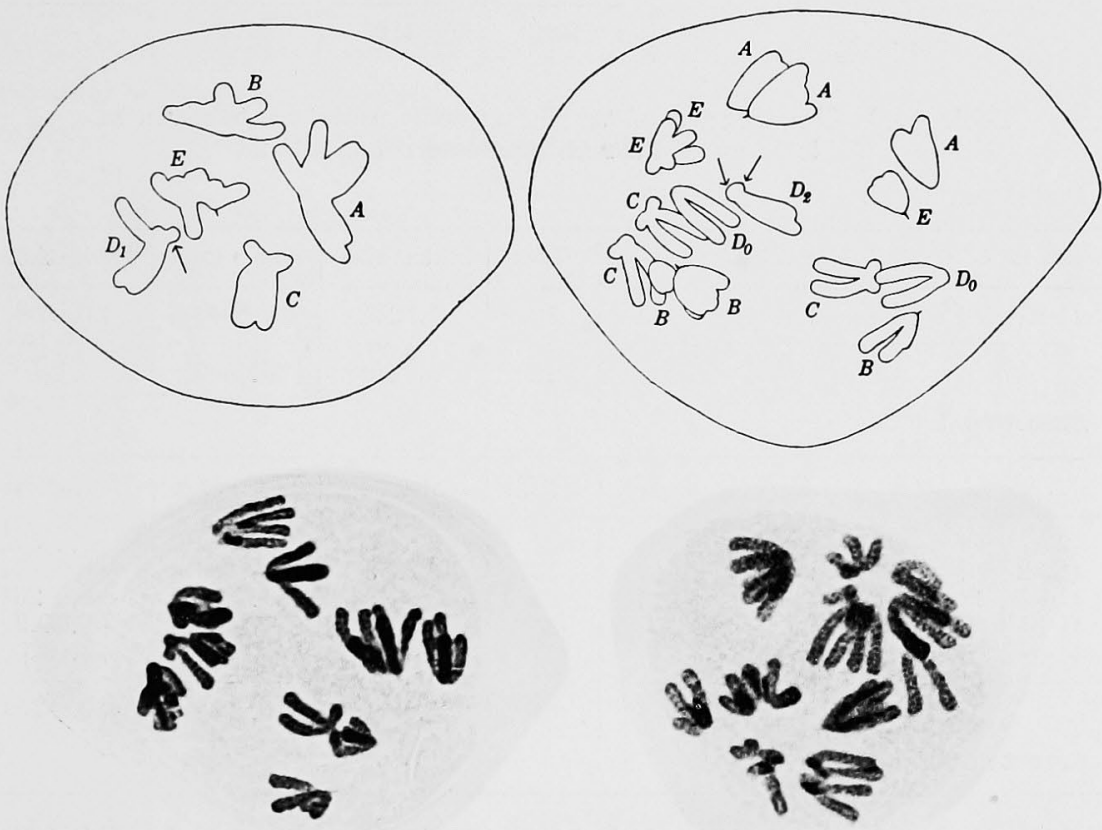

18
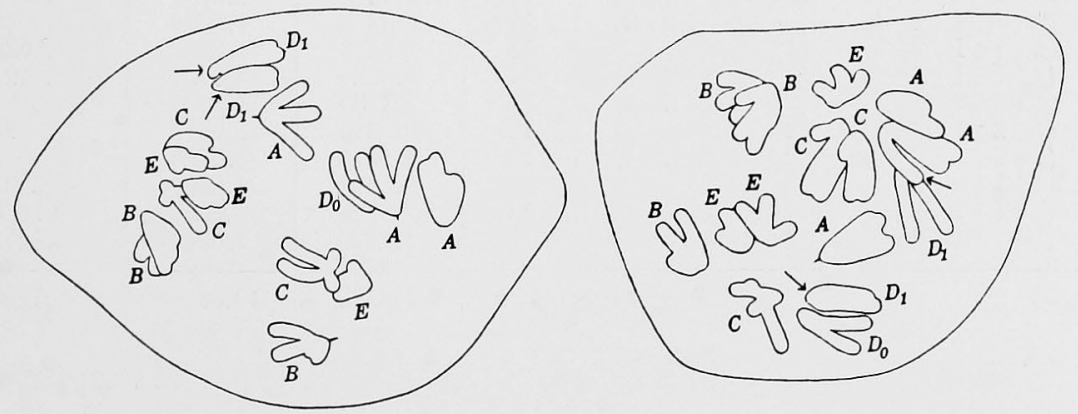

Figs. 16-19. Meiotic first divisions in PMCs of the triploid form $C C C^{-} D D^{-} D^{-}$. 16: Metaphase showing three trivalents. 17-19: Anaphases, being the chromosome assortments 5-10, 6-9 and 7-8 respectively. For the details compare the photos with the outline figures given below each photo. (Prof. H. Matsuura Photo.) $\times 747$. Outline figures: Subscript numerals under $D$-type chromosomes indicate the number of trabants, 1 and 2 representing the presence of one and two trabants respectively and $o$ the absence of any. Arrows indicate the position of trabants. 
Table 12. Assortment of chromosomes in 256 meiotic first anaphase PMCs of the triploid form $C C C^{-} D D^{-} D^{-}$

\begin{tabular}{|c|c|c|c|c|}
\hline Cbromosome assortment & $5-10$ & $6-9$ & $7-8$ & Total \\
\hline Frequency (PMCs) & 18 & 81 & 157 & 256 \\
\hline Ratio observed & 1.1250 & 5.0625 & 9.8125 & 16.0000 \\
\hline Ratio expected & 1.0000 & 5.0000 & 10.0000 & 16.0000 \\
\hline Deviation & +0.1250 & +0.0625 & -0.1875 & 0.0000 \\
\hline P.E. & \pm 0.1633 & \pm 0.3126 & \pm 0.3265 & - \\
\hline
\end{tabular}

Table 13.) Classification of the chromosome assortments given in Table 12 as to their chromosome combinations

Assortment 5-10.

\begin{tabular}{rrr|r|r|r|r}
\hline$A B C D E$ & $A B C D E$ & PMCs & Ratio obs. & Ratio exp. & Deviation \\
\hline$(1+1+1+1+1)$ & $(2+2+2+2+2)$ & 18 & 1.1250 & 1.0000 & +0.1250 \\
& Sum & 18 & 1.1250 & 1.0000 & +0.1250
\end{tabular}

Assortment 6-9.

\begin{tabular}{rr|r|r|r|r}
\hline$A B C D E$ & $A B C D E$ & PMCs & Ratio obs. & Ratio exp. & Deviation \\
\hline$(2+1+1+1+1)-(1+2+2+2+2)$ & 14 & 0.8750 & 1.0000 & -0.1250 \\
$(1+2+1+1+1)$ & $(2+1+2+2+2)$ & 15 & 0.9375 & 1.0000 & -0.0625 \\
$(1+1+2+1+1)-(2+2+1+2+2)$ & 15 & 0.9375 & 1.0000 & -0.0625 \\
$(1+1+1+2+1)-(2+2+2+1+2)$ & 20 & 1.2500 & 1.0000 & +0.2500 \\
$(1+1+1+1+2)-(2+2+2+2+1)$ & 17 & 1.0625 & 1.0000 & +0.0625 \\
& Sum & 81 & 5.0625 & 5.0000 & +0.0625
\end{tabular}

Assortment 7-8.

\begin{tabular}{rr|r|r|r|r}
\hline$A B C D E$ & $A B C D E$ & PMCs & Ratio obs. & Ratio exp. & Deviation \\
\cline { 1 - 2 }$(2+2+1+1+1)$ & $(1+1+2+2+2)$ & 11 & 0.6875 & 1.0000 & -0.3125 \\
$(2+1+2+1+1)-(1+2+1+2+2)$ & 15 & 0.9375 & 1.0000 & -0.0625 \\
$(2+1+1+2+1)-(1+2+2+1+2)$ & 15 & 0.9375 & 1.0000 & -0.0625 \\
$(2+1+1+1+2)-(1+2+2+2+1)$ & 17 & 1.0625 & 1.0000 & +0.0625 \\
$(1+2+2+1+1)$ & $(2+1+1+2+2)$ & 22 & 1.3750 & 1.0000 & +0.3750 \\
$(1+2+1+2+1)-(2+1+2+1+2)$ & 15 & 0.9375 & 1.0000 & -0.6625 \\
$(1+2+1+1+2)-(2+1+2+2+1)$ & 19 & 1.1875 & 1.0000 & +0.1875 \\
$(1+1+2+2+1)-(2+2+1+1+2)$ & 11 & 0.6875 & 1.0000 & -0.3125 \\
$(1+1+2+1+2)-(2+2+1+2+1)$ & 13 & 0.8125 & 1.0000 & -0.1875 \\
$(1+1+1+2+2)-(2+2+2+1+1)$ & 19 & 1.1875 & 1.0000 & +0.1875 \\
& Sum & 157 & 9.8125 & 10.0000 & -0.1875
\end{tabular}

Merely as to the chromosome number three types of assortment will be expected from the 5 trivalents metaphases, namely 5-10

1) Two anaphase groups in a PMC are shown with the two formulas in parentheses combined with - . The probable error for each case is the same, being \pm 0.16327 . The total sum of the deviations is 0.0000 . 
(Fig. 17), 6-9 (Fig. 18) and 7-8 (Fig. 19) and their ratio of occurrence must be 1:5:10. This expectation was proved indisputably in the observation (Table 12). To inspect more closely the mode of assortment, every one was classified regarding at the same time the number and combination of chromosomes. Thus the numerical assortment 5-10, 6-9 and 7-8 will be subdivided into 1,5 and 10 cases respectively as to the combination of chromosomes. And every combination is expected to happen with equal chance. This was also perfectly substantiated (Table 13). Consequently of the pollen grains resulting from 5 trivalents metaphase 3.1 percent will be normal haploid with one complete genom and the same percent diploid with two complete genoms, all other grains containing a complete genom and 1-4 extra chromosomes.

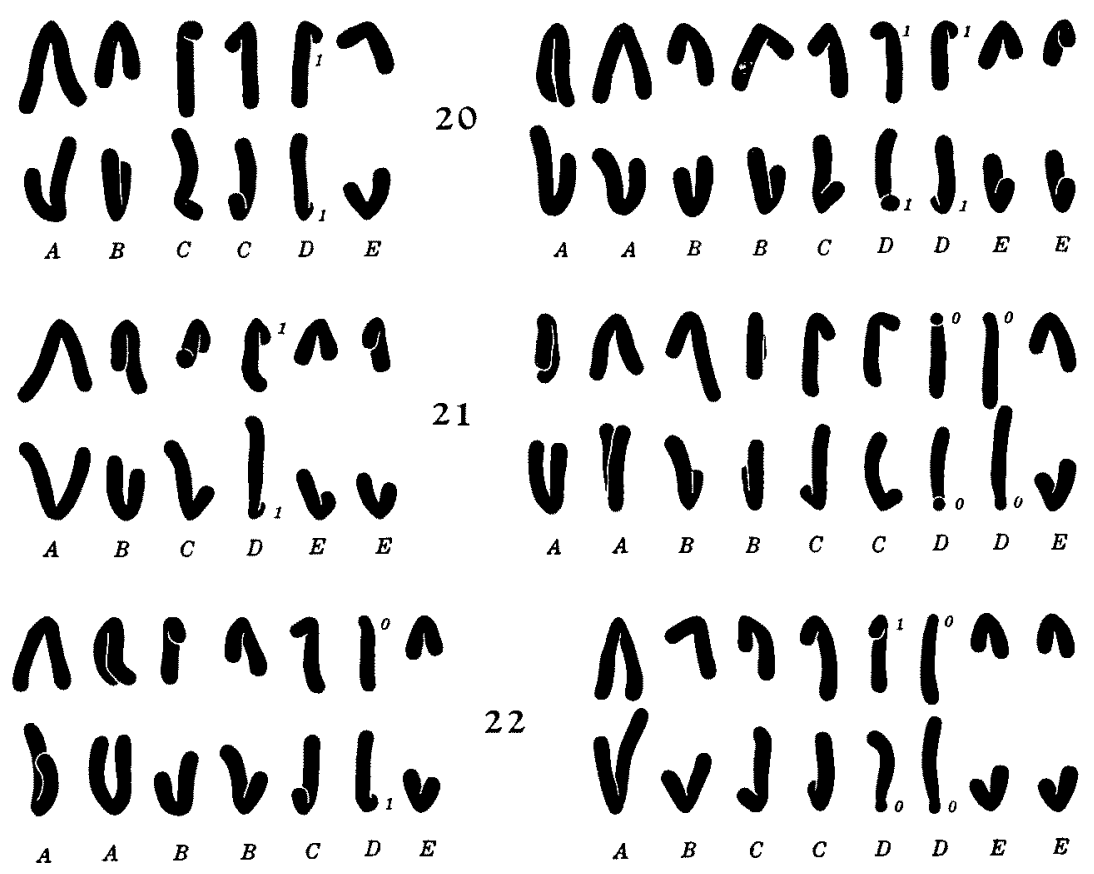

Figs. 20-22. Alinements of meiotic second anaphase chromosomes in two triploid karyotypes, being the two divisions in a PMC shown separately at both sides of the Figure number. Daughter halves are faced up and down. Numerals beside the $D$ type chromosomes indicate the presence (1) or absence (o) of a trabant. 20: Type $C C C D D D$, being the chromosome assortment 6-9. 21-22: Type $C C C^{-} D D^{-} D^{-}$, being the chromosome assortment 6-9 and 7-8 respectively. Segregation of the short arm of $D$-type chromosomes is equational in Fig. 21 and reductional in Fig. 22. $\times 870$.

Heteromorphic trivalent $D-D^{-}-D^{-}$segregates at first anaphase, as in bivalent $D-D^{-}$, reductionally as well as equationally (Figs. 1719). Their second anaphase segregation is reductional or equational 
according to the previous one (Figs. 20-22). The ratio of reductional to equational segregations is not determined, however it was apparent that equational segregation is prevailing as in bivalent $D-D^{-}$.

\section{Discussion}

1. Origin of the karyotypes. The homozygous diploid form was represented only by $C C D D$ type which spread most abundantly in the natural population, so that it seems highly pertinent to consider this type to be the prototype of the other ones. Remaining heterozygous diploids are considered to have been derived from the mating of a normal with an exceptional gamete containing a simple translocation or simple deletion, or between the latter ones.

Through all karyotypes found there were no structural changes in chromosomes $A, B$ and $E$. $C^{-}$-chromosomes observed in two diploids $C C^{-} D D, C C^{-} D D^{+}$and in one triploid karyotype $C C C^{-} D D^{-} D^{-}$have showed the same deficiency of short arm length, strongly suggesting a common origin for them. $D^{-}$-chromosome is obviously the result of simple deletion of the trabant of $D$-chromosome. The surplus length of the trabant of a $D^{+}$-chromosome is almost equal to the deficit length of the short arm of a $C^{-}$-chromosome. From these facts one may safely conclude that the simple translocation of a small segment from the short arm of $C$ to the distal end of the trabant of a $D$-chromosome to be the very cause of origin of $C^{-}$- and $D^{+}$-chromosome. However the expected multivalent association $C^{-}-C-D^{+}-D$ such as has been demonstrated in the case of Rumex (YAMAMOTO 1935) was not met with at the meiosis of a heterozygous diploid $C C^{-} D D^{+} \quad$ But, it seems highly improbable that this is decisive disproof for the above interpretation because such a circumstance is of the most expectable in considering only about 1 micron of the somatic length of the translocated segment. A similar case of frequent non-pairing between the homologous parts was demonstrated experimentally in the translocation from $A$ - to $C$-chromosome of Crepis capillaris (PETROV 1935).

As to the origin of the structural change of the chromosomes environmental factors must be responsible for it, among them the influence of temperature may be the most common and effective in nature. Recent experiments with X-radiation (LEWITSKY et al. 1934, CATCHESIDE 1935, and MAtsuURA and HAGA 1937), several chemicals (LEWITSKY and ARARATIAN 1931), aging (GERASSIMova 1935), etc., have provided many instances for such chromosome alterations. Interestingly it has been confirmed that experimental effects exerted upon various stages of development, e.g., upon seeds, young shoots, PMCs or pollen grains, are equally effectual in the formation of 
karyotypic aberration. So when and where the aberrant karyotypes of this plant have originated is undeduciable, especially in the habit of this plant with a perenial rhizome which bears flower buds for the next Spring already in the previous Autumn and with very poorly germinating seeds. The only sign is seen in the somewhat high frequency of abnormal meiosis showing fragmentation and chromatid bridge, which indicate essentially the possibility of the occurrence of deletion and translocation ( $c f$. MATsUURA and HAGA 1937).

Triploids are explained, as in many other autotriploids, as the results of fusion between a haploid and a diploid gamete. The karyotype found in triploids may also be explicable as in diploids, but with some complexity.

Formation of diploid gamete in diploids probably has been caused by environmental influences, especially by temperature as in the experimental cases in Liriope and Scilla (ShimotomaI 1927), in Lychnis (TAKAGI 1928), etc., but not excluding the possibilities by polyploidal chimera (TAHARA 1933), by the action of certain genes (BERgNer et al. 1934 and SATINA and Blakeslee 1935) or by phytopathological infection (KoSTOFF 1933), etc.

Though it is a secondary process, the production of gametes containing two complete genoms by an autotriploid, which has been definitely shown in the present study, must be added here. Such a function of autotriploids may have an important rôle in the evolution of allo- as well as autopolyploidy as proved partially in some cases, e.g., in Crepis (NAvashin 1931), in Rumex (ONO 1935), etc.

Homozygous plants with regard to $C^{-}$-, $D^{+}$- and $D^{-}$-chromosome are not found by GотоH and STOW nor by the writer as yet. What is the reason for this? One may expect the governing of the lethal mechanism as in Galtonia (NAWASCHIN 1927), Matthiola (PHILP and Huskins 1931), Petunia (Malinowski 1935), etc. The writer wishes fully to deal with these problems upon a later occasion.

2. Plant-geographical. Recent works by HAGERUP (1932 and 1933) and MATSUURA (1935) have revealed several instances in which polyploids enter into a new territory on account of change in their biological properties, resulting in a distributional differentiation between polyploids and the original form. For example in Fritillaria camchatcensis the diploid form was restricted to the alpine region, whereas the triploid grows only in low lands (MATsuURA 1935).

The case in Paris hexaphylla was in striking contrast to the above instances, diploid and triploid populations growing in contact with one another in their natural haunt. Such also occurred within the karyotypes of diploids and of triploids (Fig. 23). Diploid $C C^{-} D D$ 
and triploid $C C C^{-} D D^{-} D^{-}$were found a little apart in the area covered by the map shown in Text-figure 23. This offers further evidence for the above interpretation on the origin of karyotypes.

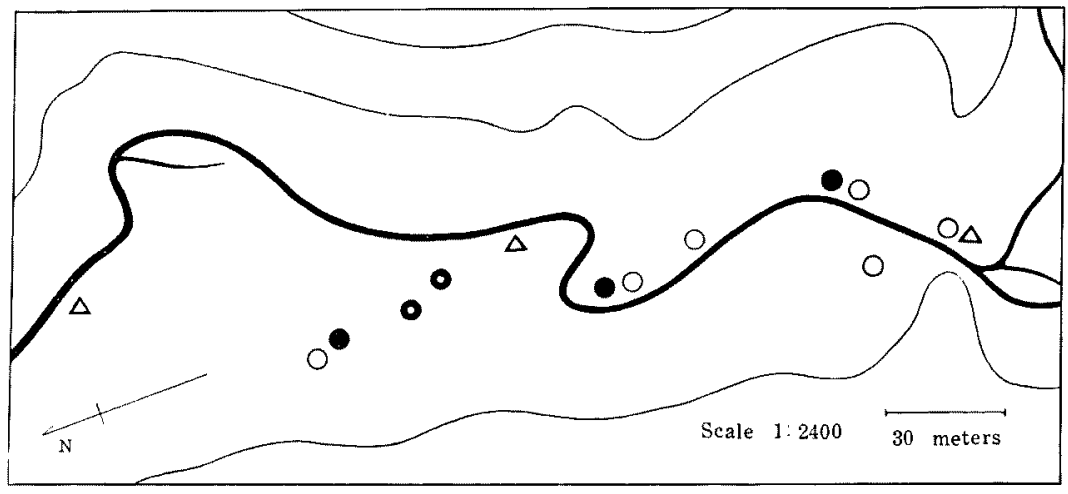

Fig. 23 A contour-line map along the little stream running at the foot of Mt. Maruyama near Sapporo, showing the occurrence of the four different karyotypes in their natural haunt. $\circ$ : Type $C C D D$. ०: Type $C C^{-} D D^{+}$. $\bullet$ : Type $C C D D^{-} . \triangle$ : Type $C C C D D D$.

Such a condition will be interpreted with most certainty to the effect that polyploidal as well as karyotypic alteration found in this plant has insufficient effect in the change of biological properties to cause a distributional or ecological differentiation.

3. Meiotic segregation of the heteromorphic chromosome pair. On account of their significance for an interpretation of meiosis in relation to some genetic phenomena, the behavior of heteromorphic chromosome pairs has been studied by several investigators, but resulting in very diverse conclusions with different materials ( $c f$. HUSKINS and SPIER 1934, and MATHER 1935). In Triticum vulgare HUSKINS and SPIER made an interpretation for the mechanism of equational and reductional segregation of the heteromorphic bivalents in relation to chiasmatype theory. Also MATHER had made a theoretical consideration on this problem, advancing the $2: 1$ ratio of equational to reductional segregation as an "equilibrium proportion" on the basis of the same theory.

In the present material heteromorphic $D$ - $D^{-}$bivalents segregated with a ratio of 1.0 reductional to 5.3 equational as to its heteromorphic short arms. This ratio is not expectable directly from MATHER's formula. According to him such a proportion "will depend on the mean and variance of the chiasma frequency distribution" on the short arm. However, in such a bivalent which retained paired at metaphase very probably at the kinetochore as in Trillium kamtschaticum, the behavior of the kinetochore must be taken in consideration 
when analysing the problem ( $c f$. MatsuURa 1937). The writer hopes to leave the final conclusion to the time when other statisticial data are available.

4. Segregation of trivalents. There are advanced many hypotheses of the karyokinetic mechanism ( $c f$. BLEIER 1931 and KOLLER 1934). Among them, though some parts are objectionable, BLEIER's hypothesis seems to be the most elaborated one, interpreting many special modes of karyokinesis with consistent principles carried out by the cooperation of autonomous movement of chromosomes, repulsion between split halves or components of a paired chromosomes, spindle bipolarity and the division of spindle substance.

According to BLEIER, at metaphase three kinetochores of a trivalent mutually repulse each other potentially if they are not separated until the anaphase and visibly if they separated already before the metaphase, in the latter case the pairing being retained only by chiasmata (Fig. 24). The former case is represented by the present material and the latter is known in many other plants. At metaphase trivalents are subjected to the influence of spindle bipolarity, forming a metaphase plate. In equatorial plane, BLEIER's “Gleichgewichtszone”, three kinetochores of a trivalent must be disposed in principle, to attain a metaphaseanaphase equilibrium as shown in Textfigure 24 by the cooperation of repulsion between the three kinetochores and the bipolarity of spindle. Although it is a special case one may indisputably prove such a disposition in a tripartite sex chromosome such as in Rumex (cf. ONo 1935 and YAMAMOTO 1935).

At anaphase the kinetochores separate if unseparated before that time, and chromatids within a chromosome repulse one another, if they are formed, cancelling all chiasmata. After this stage the chromosomes will behave as those derived from the bivalents, kinetochore $a$ and $b$ going pole $P_{1}$ and $c$ to $P_{z}$ (Fig. 20). Thus the anaphase segregation of a trivalent is regular determined by the metaphase dis-

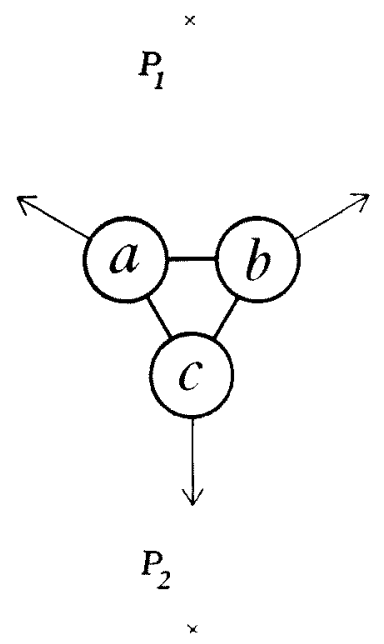

Fig. 24. A diagrammatic representation of the metaphase equilibrium of a trivalent, indicating $P$ poles, $a$, $b$, and $c$ kinetochores which repulsing one another in the direction shown by arrows. position of the three kinetochores, in other words, it is not determined by the so-called random distribution of the extra member. 
However it is evident that the metaphase disposition of three kinetochores is determined by chance, i.e. the position of $c$ in Textfigure 24 may be occupied also by $a$ or $b$ in equal chance with $c$. And it is independent between the trivalents. So self-evidently only gametes with $n-2 n$ chromosomes comprising at least a complete haploid set must result from metaphases with the trivalents corresponding to the basic chromosome number $n$. The present study has offered conclusive evidence for this.

\section{Summary}

1) Six karyotypes were distinguished in Paris hexaphylla CHAM. which has a basic chromosome number 5 consisting of morphologically distinguishable chromosomes $A, B, C, D$ and $E$. Four of them were diploid and two triploid:

\begin{tabular}{|c|c|c|c|c|}
\hline \multicolumn{2}{|c|}{ Diploids $(2 \mathrm{n}=10)$} & \multicolumn{3}{|c|}{ Triploids $\quad(2 \mathrm{n}=15)$} \\
\hline Karyotype 1 & $C C D D$ & Karyotype & 1 & $C C C D D D$ \\
\hline,,$\quad 2$ & $C C^{-} D D$ & ," & 2 & $C C C^{-} D D^{-} D^{-}$ \\
\hline , & $C C C D D^{-}$ & & & \\
\hline ,, & $C C^{-} D D^{+}$ & & & \\
\hline
\end{tabular}

Karyotypic aberration concerns only chromosomes $C$ and $D$. $C^{-}$- and $D^{+}$-chromosome were suggested as having resulted from simple translocation from $C$ short arm to trabant of $D$. $D^{-}$-chromosome was interpreted as originated from a simple deletion of the whole trabant of $D$. Except the homozygous diploid $C C D D$ and the triploid $C C C D D D$ all other karyotypes were heterozygous as to $C$ - or $D$-type chromosome or both of them.

2) There was no distributional or ecological difference between diploids and triploids and between the karyotypes, showing that polyploidy and the karyotypic changes found in this plant are not sufficiently effectual to cause a biological differentiation.

3) The heteromorphic constitutions of $D-D^{-}$bivalents and $D-D^{-}-D^{-}$trivalents were easily discerned at meiosis in PMCs. Heteromorphic short arm segregates equationally as well as reductionally at first anaphase. The ratio of reductional to equational segregation was $1.0: 5.3$ in $C \quad C \quad D^{-} D$ diploid.

4) Metaphase-anaphase behavior of the trivalents was discussed on the basis of observations on anaphase segregation of 5 trivalents metaphases. Anaphase behavior of the trivalent is a regular one for itself, segregating 1 to 2 chromosomes. Thus from 5 trivalents metaphases only the gametes with $5-10$ chromosomes comprising at least a complete haploid set must result. This was really verified in the present study. 
It is the writer's pleasure to express his sincere thanks to Professor H. MatsuURA under whose valuable suggestions and encouragement the present work was carried out.

\section{Literature Cited}

Bergner, A. D., Cartledge, J. L. and Blakeslee, A. F. 1934. Chromosome behavior due to a gene which prevents metaphase pairing in Datura. Cytologia 6: 19-27.

Bleier, H. 1931. Zur Kausalanalyse der Kernteilung. Genetica 13:27-76.

Catcheside, D. G. 1935. X-ray treatment of Oenothera chromosomes. Genetica 17: 313-341.

Gerassimova, H. 1935. The nature and causes of mutations II. Transmission of mutations arising in aged seeds: Occurrence of "homozygous dislocants" among progeny of plants raised from aged seeds. Cytologia $6: 431-437$.

Gotoh, K. und Stow, I. 1930. Karyologische Studien an Paris und Trillium (Vorl. Mitt. in Japanisch). Japan. Journ. Gen. 5: 114-117.

- 1933. Karyologische Studien an Paris und Trillium. Japan. Journ. Gen. 8: 197-203.

Haga, T. 1934 a. The comparative morphology of the chromosome complement in the tribe Parideae. Journ. Fac. Sci. Hokkaido Inp. Univ. Ser. V. 3: 1-32.

$-1934 \mathrm{~b}$. On the karyotypes and their gametes of Paris quadrifolia L. var. obovata REGEL et Tul. (Prelim. note in Japanese with Engl. Résumé). Bot. Mag. (Tokyo) 48 : 241-248.

- 1935. On nuclear polymorphism in Paris hexaphylla Cham. (Prelim. note in Japanese). Japan. Journ. Gen. 11: 286-287.

- 1937. Genom and polyploidy in the genus Trillium. Japan. Journ. Gen. (In the press).

Hagerup, O. 1932. Ưber Polyploidie in Beziehung zu Klima, Ökologie und Phylogenie. Chromosomenzahlen aus Timbktu. Hereditas 16: 19-40.

- 1933. Studies on polyploid ecotypes in Vaccinium uliginosum L. Hereditas 18 : $122-128$.

Huskins, C. L. and Spier, J. D. 1934. The segregation of heteromorphic homologous chromosomes in pollen mother-cells of Triticum vulgare. Cytologia 5:269277.

Koller, P. C. 1934. The movements of chromosomes within the cell and their dynamic interpretation. Genetica 16: 447-466.

Kostoff, D. 1933. A contribution to the sterility and irregularities in the meiotic processes caused by virus diseases. Genetica 15: 1 3-114.

Kuhn, E. 1928. Zur Zytologie vom Thalictrum. Jahrb. wiss. Bot. 68: 382-430.

Lesley, M. M. and Lesley, J. W. 1935. Heteromorphic A chromosomes of the tomato differing in satellite size. Genetics $20: 568-580$.

Lewitsky, G. A. and Araratian, A. G. 1931. 'Transformations of chromosomes under the influence of X-rays. Bull. A ppl. Bot. Gen. Pland Breed. $27: 265-303$.

Lewitsky, G., Shepeleva, H. and Titova. N. 1934. Cytology of $F_{1}, F_{2}$ and $F_{3}$ of Xrayed Crepis capillaris WALLR. Plant Industry USSR 11: 3-9.

Malinowski, E. 1935, Studies on unstable characters in Petunia. I. The extreme Hower type of the unstable race with mosaic color patterns. Genetics 20: $342-356$.

Mather, K. 1935. Reductional and equational separation of the chromosomes in bivalents and multivalents. Journ. Gen. 30:53-78.

Matsuura, H. 1935. On karyo ecotypes of Fritillaria camschatcensis (L.) KeRGaWler. Journ. Fac, Sci. Hokkaido Imp. Univ. Ser. V. 3:219-232.

- 1937. Chromosome studies on Trillium kamtschaticum Pall. III. The mode of chromatid disjunction at the first meiotic metaphase of the PMC. Cytologia 8 : 142-177.

- and Haga, T. 1937. Do. VI. The effects of X-radiarion upon the meiotic cbromosomes. (In preparation). 
Medwedewa, G. B. 1929. Über die „Trabanten“" bei Crepis dioscoidis L. (Vorläuf. Mitt.) Zeits. Zellf. mikroskop Anat. 10: 150-163.

Navashin, M. 1933. On the chromatin deficiency in Crepis leading to partial sterility and to forming of a heteromorphic chromosome pair. Z.I. A. V. 63: 218-223.

Nawaschin, S. 1912. Zellkerndimorphismus in somatischen Zellen von Galtonia candicans. Bull. Acad. Sci. St. Peterburg 6:373-385. (Russian, cited after S. Nawaschin 1927 and M. Navashin 1933).

- 1927. Zellkerndimorphismus bei Galtonia candicans DEs. und einiger verwandten Monokotylen. Ber. Deutsch. Bot. Gesel. 45: 415-428.

Ono, T. 1935. Chromosomen und Sexualität von Rumex acetosa. Sci. Rep. Tôhoku Imp. Univ. \& Ser. Biol. 10: 41-210.

Petrov, D. F. 1935. The reduction division in karyotypical aberrants of Crepis capillaris Wallr. Bull. Appl. Bot. Gen. Plant Breed. Ser. II. 8: 29-58, 169-183 (Russian with English résumé).

Philp, J. and Huskins, C. L. 1931. The cytology of Matthiola incana R. Br., especially in relation to the inheritance of double flowers. Journ. Gen. $24: 359-404$.

Satina, S, and Blakeslee, A. F. 1935. Cytological effects of a gene in Datura which causes dyad formation in sporogenesis. Bot. Gaz. 96: 521-532.

Shimotomai, N. 1927. Ü̉ber Störungen der meiotischen Teilungen durch niederige Temperature. Bot. Mag. (Tokyo) 41: 147-160.

Stow, I. 1935. On the correlation between the satellite of chromosome and the leaf shape in Parideae from Hokkaido. Journ. Fac. Sci. Hokkaido Imp. Univ. Ser. V. $4: 31-46$.

Tahara, M. 1933. Chromosome morphology in Smilacina japonica. Sci. Rep. Tôhoku Imp. Univ. 4 Ser. Biol. 8: 33-37.

Takagi, F. 1928. The influence of the higher temperature on the reduction division of the pollen mother cells of Lychinis sieboldii, van HouTTE. Sci. Rep. Tôholku Imp. Univ. \& Ser. Biol. 3: 461-466.

Yamamoto, Y. 1935. Karyogenetische Untersuchungen bei der Gattung Rumex. IV. Ein Fall von einfacher Translocation bei Rumex acetosa L. Cytologia 6 : $407-412$.

POSTSCRIPT. With respect to the mode of opening out of the heteromorphic short arms of $D-D$ - bivalent, it was stated in the present paper that they always open in the plane of reduction, but extensive reinvestigation newly undertaken revealed the interesting fact that the concerning heteromorphic arms open in the equational (E) as well as in the reductional plane $(\mathrm{R})$. The ratio $\mathrm{E}: \mathrm{R}$ was $2: 1$ (actually 202:98 in a

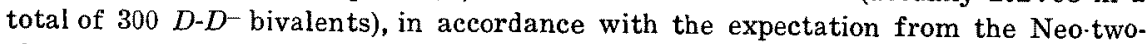
plane theory adovocated by Professor H. Matsuura*; in other respects the given data remain unaltered. For further informations readers may refer to a later publication by the present writer.

(T. Haga, May 27, '37).

* Matsuura, H. 1937. On the chiasma theories for the mechanism of crossing over. Japan. Journ. Gen. 13: 41-42 (in Japanese). 